\title{
Contribuições do Design para o Ensino de Ciências por Investigação
}

\section{Contributions of Design Science for Inquiry-Based Science Education}

\section{Gabriel da Silva Bruno ${ }^{(0)}$ Brasil \\ Paula Carolei ${ }^{\circledR}$ Brasil}

Este artigo apresenta uma investigação teórico-metodológica descritiva e propositiva que explora o potencial do Design para o Ensino de Ciências por Investigação, tendo como objetivo a ampliação dos seus formatos de prática e a superação de algumas dificuldades em situações nas quais a lógica projetual baseada em Design pode ser uma alternativa para se trabalhar com as situações-problemas, desenvolvendo constructos físicos ou teóricos que, para tal, mobilizam conhecimentos específicos e interdisciplinares. Partimos da leitura de algumas das abordagens e metodologias associadas ao processo investigativo e criativo. Explicitamos reflexões e possibilidades de encontro entre o Ensino de Ciências por Investigação e o Design, partindo da premissa de que tanto a Ciência como o Design são processos construtivos que trabalham com modelos. Essa aproximação, que denominamos como Ensino de Ciências por Projeto Investigativo (ENCIPI) valoriza os percursos trilhados e desenvolve pontos que potencializam a prática investigativa, como o aprender a lidar com o erro e com a reconfiguração de modelos. Temos como resultado a apresentação de seis etapas para o desenvolvimento de projetos investigativos articulados ao Design e influenciados por outras metodologias e abordagens. São elas: estabelecer e programar; expandir e aproximar; propor; criar; validar e aprimorar; e comunicar, implementar e aprender, e orientamos os principais movimentos de cada etapa, para professores e alunos, assim como os recursos envolvidos para as mesmas.

Palavras-chave: Ensino de Ciências; Ensino por Investigação; Projeto; Design; Projeto Investigativo.

This article presents a descriptive, theoretical-methodological, and propositive investigation that explores the potential of Design Science for Inquiry-Based Science Education, aiming for the expansion of practice formats and overcoming some difficulties in situations in which a Design Science research model can be an alternative to work around problems, developing physical or theoretical constructs that mobilize specific and interdisciplinary knowledge for this purpose. We start by reading some of the approaches and methodologies associated with the investigative and creative processes. We present reflections and possibilities of convergence between Inquiry-Based Science Education 
and Design Science, starting from the premise both are constructive processes that work with models. This approach, which we call Science Education Through Inquiry-Based Project, addresses the in-betweens and develops points that enhance the inquiry-based practice, such as learning to deal with error and with the reconfiguration of models. As a result, we present a six-step proposal to develop inquiry-based projects related to Design Science and influenced by other methodologies and approaches. The six steps are: establishing and scheduling; expanding and approximating; proposing; creating; validating and improving; communicating, implementing and learning. We then present the main movements of each step for teachers and students and the resources that involve them.

Keywords: Science Teaching; Inquiry-Based Learning; Project; Design Science; InquiryBased Projects.

\section{Introdução}

Diante dos diversos desafios do ensino e da aprendizagem de ciências na educação básica e das mobilizações que surgem para superá-las, escolhemos nos debruçar sobre o Ensino de Ciências por Investigação (ENCI), que tem a atitude investigativa como forma de condução das atividades em sala de aula.

Entendemos que o movimento investigativo não parte de uma estrutura pronta de aulas focadas na memorização, apresentação de estruturas e funções ou descrição de relações, para, no final ter uma demonstração ou aplicação. Para Carvalho (2013) passou-se a "privilegiar mais os conhecimentos fundamentais dando atenção ao processo de obtenção desses conhecimentos." (p. 1). Assim, a ação investigativa é, em nossa visão, aprender ciência fazendo ciência. Não é decorar ou assimilar os modelos prontos, mas construir modelos, explicações, testes e simulações.

Nessa perspectiva, saber ciências é mais do que saber sobre os fenômenos, conceitos e leis da ciência. É também, segundo Driver e colaboradores (2000) citado por Trivelato e Tonidandel (2015) saber a relação desses fenômenos com outros, por que são importantes e como são produzidos os conhecimentos a respeito.

Existe, portanto, a necessidade de se trabalhar em sala de aula situações de aprendizagem mais complexas, que se aproximem das situações encontradas na realidade presente e futura dos alunos e que os faça julgar e relacionar os conhecimentos construídos. Entendemos, assim, que se o ambiente (escolar)

[...] não lhes fizer novas exigências e não estimular o seu intelecto, obrigando-os a defrontarem-se com uma sequência de novos objetivos, o seu pensamento não conseguirá atingir os estágios de desenvolvimento mais elevados, ou atingi-lo-á apenas com grande atraso (Vygotsky, 2008, p. 61).

$\mathrm{Na}$ busca de novos potenciais metodológicos para tal, o alinhamento do ENCI ao Design é coerente na medida que consideramos ambos como processos construtivos e simultaneamente investigativos, abrindo possibilidades para novos tipos de investigação 
em sala de aula.

Embora a ciência procure explicar enquanto o Design busca criar, para Burnette (2005a), ambos usam os mesmos modos de pensar, trabalhando com informações e referências relevantes; variáveis complexas; hipótese e abordagens conceituais; desenhos e condições experimentais; técnicas de coleta de dados em comum, etc.

O Design pode ser entendido como uma atividade de criação, uma sequência de eventos e procedimentos, preenchidos pelo pensamento para a criação do que está sendo projetado (Miller, 1988), envolvendo várias atividades relacionadas ao pensar: contemplar, falar, escrever, desenhar, modelar, construir, etc.

O modo pelo qual os designers problematizam situações complexas configuram certo tipo de inteligência que pode ser proveitosamente utilizada como prática educativa visando preparar os alunos para os desafios da vida adulta contemporânea (Martins, \& Couto, 2016).

Como atividade, o design opera a junção do abstrato com o concreto, ou seja, dá forma material a conceitos intelectuais. Em outras palavras, o design em sua essência, envolve a conceituação e, através do emprego da tecnologia, a materialização de idéias. Implica a concepção, o desenvolvimento e a construção de objetos, sistemas ou serviços. Trata-se de uma atividade projetual e como tal, exercita a previsão - pré+visão -; o atirar longe, o lançar para diante, lançar à frente; o projetar - projectare (Fontoura, 2002, p. 92, destaques no original).

A articulação entre o Ensino de Ciências por Investigação e o Design pode trazer para o ENCI novas discussões e possibilidades quanto as práticas, seus formatos e objetivos.

\section{O Ensino de Ciências e o Ensino de Ciências por Investigação}

Há uma preocupação crescente em colocar a Alfabetização Científica ${ }^{1}$ como objetivo fundamental do ensino de Ciências em toda a formação básica. Para Sasseron e Carvalho (2011) a alfabetização científica envolve a compreensão básica de termos, conhecimentos e conceitos científicos fundamentais, assim como a compreensão da natureza das ciências, dos fatores éticos e políticos que circundam a prática científica e as relações existentes entre ciência, tecnologia, sociedade e meio-ambiente. Ainda segundo tais autoras, essa preocupação ganha base, respaldo e consistência devido uma percepção da necessidade emergente de formar alunos para atuação na sociedade atual, largamente cercada por artefatos da sociedade científica e tecnológica ${ }^{2}$.

1 Existe uma série de conceitos com pontos comuns e divergentes, como letramento científico e enculturação científica. Adotamos "alfabetização científica" por considerá-la mais abrangente e coerente com o que propomos através do Ensino de Ciências por Projeto Investigativo.

2 Vale destacar que os produtos da ciência e da tecnologia (colocados em pauta na alfabetização científica) nada mais são do que artefatos - o que aproxima a ciência do Design (já que o Design se dedica a construção dos mesmos). Uma de nossas colocações é de que compreender a lógica do Design (e não apenas da ciência) pode contribuir para a alfabetização científica na medida que explora os artefatos, seu processo construtivo, seus cenários de uso e as demandas que levaram a produção daqueles artefatos. 
Sobre as tendências metodológicas que vão em direção às demandas brevemente apresentadas, uma alternativa em destaque é o Ensino por Investigação (Inquiry-Based Learning).

Ao longo dos anos, diversas terminologias foram criadas, para denominar propostas que enfatizavam atividades didáticas investigativas, como: aprendizagem por descoberta; aprendizagem por resolução de problemas, ensino por investigação e ensino como investigação (Rodrigues, \& Tarciso, 2008; Zômpero, \& Laburú, 2011). Apesar dos diferentes termos e seus empregos, Zômpero e Laburú (2011) ressaltam que é consenso entre os pesquisadores que a perspectiva do ensino com base na investigação "possibilita o aprimoramento do raciocínio e das habilidades cognitivas dos alunos, e também a cooperação entre eles, além de possibilitar que compreendam a natureza do trabalho científico" (p. 2).

Segundo Carvalho (2004), para uma atividade ser considerada investigativa, ela não deve contemplar apenas a observação dos fenômenos e manipulação de objetos por parte dos estudantes, mas demandar ações de reflexão, discussão, explicação e relato.

Nesse sentido, o Ensino de Ciências por Investigação torna-se uma alternativa para o desenvolvimento de atividades nas quais as "verdades prontas" (Motokane, 2015) são colocadas em questão em um ambiente de curiosidade, situações complexas e levantamento de hipóteses.

Para Carvalho (2013), ao propor uma questão/problema, o professor oferece aos alunos a possibilidade de raciocinar, cabendo a ele a tarefa de orientar e encaminhar as reflexões dos estudantes na construção do novo conhecimento. Essas questões permitem que os alunos não apenas tenham acesso a dados e lhes atribuam significado, mas também que construam conclusões a partir de relações traçadas entre os dados e as teorias da ciência (Trivelato, \& Tonidandel, 2015).

No ensino de ciências por investigação, segundo Sasseron (2013), os problemas podem ser apresentados de diversas formas, desde problemas experimentais, demonstrações investigativas, ou problemas envolvendo trabalhos com figuras, textos, gráficos, etc. Esses formatos estão relacionados às condições disponibilizadas e especificidades do que se investiga. A mesma autora enfatiza que toda investigação envolve um problema, o trabalho com dados, informações e conhecimentos já existentes, o levantamento e teste de hipóteses e a construção de explicações.

[...] "a leitura de um texto pode ser investigativa tanto quanto um experimento de laboratório. Não importa a forma de atividade que venha a aparecer: o essencial é que haja um problema a ser resolvido; e as condições para resolvê-lo são muito importantes, havendo necessidade de se atentar para que se façam presentes" (Sasseron, 2013, p. 43).

Mesmo que na literatura já exista a indicação de que nas atividades de ENCI os problemas e as investigações possam ter diversas formas (Sasseron, 2013), queremos 
formalizar ${ }^{3}$ um tipo de olhar sobre o problema: pelo Design, o que modifica parte da estrutura da investigação a ser realizada e contribui na superação algumas dificuldades percebidas.

\section{Críticas e Particularidades}

Entendemos que um percurso investigativo baseado apenas na compreensão de fenômenos ou leis naturais pode apresentar, em situações didáticas, algumas limitações que se tornam evidentes. Isso acontece quando se foca apenas na descoberta e explicitação das relações entre as variáveis, o que pode ser ampliado quando se percebe que a própria explicação é um modelo que pode ser aprimorado com o aumento da complexidade da descrição e com a descoberta de outras variáveis. Essa é a grande diferença de aprender ciência aceitando a explicação de um fenômeno dado por alguém ou tentando observar, descrever, explicar o que é observado, compreendido, descoberto, e ir melhorando essa explicação a cada nova dimensão percebida.

Algumas discussões sobre o ensino de Biologia por investigação foram motivadoras para alguns pontos que aqui questionamos e visamos contribuir para sua superação. Acreditamos que algumas das questões apontadas podem ser desafios comuns também às outras ciências da natureza, quando em situações de aprendizagem. Além disso, o Design já vem sendo utilizado em práticas pedagógicas de diferentes formas com diversos ganhos (Fontoura, 2002), o que nos encoraja a propor e discutir esse tipo de articulação.

Como fatores positivos ao Ensino de Biologia por investigação, temos que muitos dos conhecimentos biológicos são amplamente veiculados pela mídia, além do fato de que a vida está relacionada com diversos assuntos do cotidiano, favorecendo a abordagem de problemas relacionados à realidade dos estudantes (Moreira, Souza, \& Almassy, 2014). Mas, para Trivelato e Tonidandel (2015) do ponto de vista das práticas científicas, nem todos os temas da Biologia são investigados com procedimentos experimentais. As narrativas históricas e a comparação de evidências, por exemplo, são metodologias próprias da Biologia Evolucionista. Assim, o ensino de ciências por investigação, no contexto da Biologia, poderia utilizar outras formas de investigação.

"Com relativa frequência, as atividades experimentais são de difícil implementação no ensino de Biologia - as montagens com seres vivos requerem vários dias de observação; os resultados podem ser diferentes para cada indivíduo testado sob as mesmas variáveis; a manutenção ou a experimentação com seres vivos envolve problemas práticos e éticos; os resultados são verificados por meio de evidências indiretas, etc. Pode-se imaginar que, com tais dificuldades para a realização de atividades experimentais, a proposição

\footnotetext{
3 As práticas de Design não são exclusividade aos profissionais da área. A todo momento executamos atividades como levantamento de demandas, prototipação, iteração (melhoramento), entre outras. Assim, pode existir na literatura exemplos de práticas de ENCI com problemas de Design não intituladas como tal. Dizer que queremos formalizar esse tipo de problema significa dizer que, neste caso, os problemas vão ser definidos para serem investigados e atendidos por um processo de design (dos alunos), cientes e munidos de todos os recursos necessários para tal - o que muda parte do percurso a ser percorrido na resolução.
} 
de sequências investigativas para o ensino de Biologia tenha, pelo menos de início, uma redução de repertório." (Trivelato, \& Tonidandel, 2015, p. 4)

É também necessário que se supere o falso pensamento de que a vida se estabelece como uma interação mecânica de partes de um todo (Moreira et al., 2014; Scarpa, \& Silva, 2013; Trivelato, \& Tonidandel, 2015). Além disso, há um ponto que relaciona a aplicabilidade e a relevância (cultural, social ou política) das questões provocativas/ problemáticas no ensino de ciências por investigação (Solino, \& Gehlen, 2014).

Dessa forma, os pontos que colocamos como motivadores para uma outra abordagem para a investigação em sala de aula, partindo de alguns desafios encontrados na Biologia são:

1. Há na Biologia diversas questões pautadas em conceitos, e não em leis (o que demanda uma outra forma de trabalho com dados, que pode não ser apenas experimental, e exige uma modelização teórica aprofundada);

2.Mesmo questões experimentais podem não ser viáveis por motivos éticos, disponibilidade de tempo, ou pela própria natureza da questão;

3. É interessante que a questão-problema seja relevante para os alunos, de forma a manter o engajamento e facilitar o reconhecimento dos contextos de aplicação.

4. Conhecer somente os modelos investigativos mais utilizados nas ciências da natureza, pode, para nós, criar visões errôneas sobre as outras formas de investigação ${ }^{4}$.

Em busca de novos potenciais metodológicos para o ENCI, vemos no Design um caminho de resolução para esses pontos, devido sua dimensão processual e projetual.

\section{Design}

Mais do que puramente processo, entendemos Design aqui, também, como um conjunto de conhecimentos e procedimentos, um tipo de atitude do conhecer baseada, no ato de projetar. Assim: "um modo de pensar/raciocinar, uma cognição voltada à concepção e prototipagem de novos objetos e/ou sistemas” (Martins, \& Couto, 2016, p. 2).

A ciência é um processo. Ela separa um fenômeno das complexidades da situação na qual está inserido e procura abstrair princípios generalizáveis através da observação e ou da experiência. As atividades científicas, na sua maioria, são desenvolvidas para testar e comprovar hipóteses levantadas previamente. Fazem uso de procedimentos específicos, desenvolvidos para minimizar as possibilidades de erros. O design dela se

4 Em um trabalho anterior (Bruno, \& Carolei, 2018), acompanhamos a produção científica de estudantes de educação básica sobre um artefato tecnológico. Os projetos pertenciam a diversas áreas e foi possível verificar que, em alguns casos, os autores tratavam situações complexas como variáveis simples, aplicando, por exemplo, questionários em cenários que demandavam um outro desenho metodológico. Outros tinham objetivo de "mostrar que", de forma prejudicial ao caráter investigativo do processo. Parte desses trabalhos também apontavam a palavra mostrar relacionada "a todos/às pessoas/à população", etc. Isso nos diz um pouco sobre como esses alunos enxergam a produção científica. Assim acreditamos que deve haver uma variedade nos modelos de investigativos utilizados por esses alunos, compreendendo diferentes tipos de pesquisa científica. 
aproxima quando é também considerado um processo (Archer, 1991) e neste sentido, gera hipóteses, objetiva, através do seus resultados tangíveis, atender a uma necessidade particular, produzindo resultados praticáveis, que envolvem diversos valores tecnológicos, econômicos, mercadológicos, estéticos, ecológicos, culturais e éticos, que são determinados pelo contexto funcional, comercial e social, no qual estes resultados aparecem. (Fontoura, 2002, p. 95).

As metodologias do Design têm contribuído para avanço de diversas áreas, como Medicina, Engenharia, Gestão, Educação, entre outras. Um dos motivos para tal contribuição é o pensamento processual que o Design possui, com atenção ao público, cenário, condições, resultados obtidos, esperados, aos caminhos possíveis, escolhidos, etc.

Na Educação, uma das manifestações mais populares do Design se dá pelo Design Thinking (DT), tanto na formação de professores como na condução de projetos em/para a Educação (tendo geralmente como um dos principais pontos a consideração empática com os sujeitos envolvidos). O Design Thinking possui as fases de imersão, interpretação, ideação, experimentação e evolução, ampliando em cada fase a compreensão do contexto de um problema (Vianna et al., 2012), sendo o DT uma das abordagens do Design, entre outras, como a Design Research e o Design Especulativo (Dunne, \& Raby, 2013). O que difere cada uma dessas abordagens, de forma geral, são os objetivos e os tipos de solução que se espera criar, assim como o percurso trilhado para que se chegue a tal. Criar soluções com foco na empatia e na participação, idear soluções com valor, utilidade e relevância, propor soluções nunca antes vistas, são alguns focos dessas abordagens.

Apesar do caráter profissional da disciplina de Design, é possível praticá-lo sem conhecimento de que se pratica - embora, neste caso, perde-se o potencial de estímulo à criação e inovação (Bertoldi et al., 2011).

Vale destacar que os produtos desenhados/construídos não são apenas soluções físicas (muito menos gráficas ${ }^{5}$ ). O Design pode resultar em produtos do tipo físico, temporal, conceitual e relacional (Miller, 1988), por exemplo.

Em sala de aula, mesmo que não seja de forma consciente, diversas atividades comuns ao Design são desenvolvidas. Em pesquisa realizada por Bertoldi e colaboradores (2011), buscou-se que alunos de uma escola pública, identificassem as atividades de design presentes em suas práticas escolares diárias. Entre as respostas dos alunos verificou-se uma maior presença do "interpretar", "pesquisar", "melhorar", "solucionar", "desenhar", "observar" e "construir", mas um menor reconhecimento de momentos que fosse necessário "conceituar", “construir", "criar”, "planejar”, "projetar”, "refletir", "relatar”, entre outros.

No Brasil, o potencial do Design aplicado à Educação tem ganhado espaço. No exterior, existem alguns exemplos do Design incorporado às práticas educativas de forma compulsória, complementar ou oficialmente recomendada (Fontoura, 2002).

5 No português, o termo equivalente ao "design" seria "desenho", que originalmente tinha o mesmo significado. Com o dinamismo da língua, o termo "desenho" sofreu uma simplificação em seu significado e passou a ser entendido principalmente como forma de representação (Fontoura, 2002). Entretanto, como dito na seção "Introdução" deste trabalho, design envolve o atirar longe, o lançar para diante, lançar à frente; o projetar. 
Em seu trabalho de doutoramento, Antônio M. Fontoura, identificou e organizou 23 diferentes inserções do Design na educação básica no mundo todo, sendo sua proposta de Educação através do Design uma referência nacional para ações que explorem o potencial do Design na educação básica. Este autor também é uma das principais influências para este trabalho, como será evidenciado ao longo deste artigo.

\section{Objetivo}

O objetivo deste trabalho é propor uma ampliação dos formatos de práticas para o Ensino de Ciências por Investigação, visando a superação de algumas dificuldades em situações nas quais a lógica projetual somada ao Design pode ser uma alternativa para se trabalhar as situações-problemas. Isso porque o Design é um tipo de atividade construtiva e investigativa, que muito tem em comum com a ciência, mas traz outras formas para condução dos seus processos.

Para tecer essa articulação ENCI-Design, trazemos leituras sobre algumas metodologias e abordagens. O objetivo para essas leituras foi identificar pontos que poderiam contribuir na proposição de um novo formato de atividades para o ENCI, reunindo e articulando aspectos investigativos e projetuais de outras metodologias e abordagens, que também visam uma formação que supere o consumo, e consiga atingir a compreensão e construção da complexidade de modelos, conhecimentos, artefatos e eventos que nos cercam diariamente.

Trata-se de uma proposta inédita, e os caminhos aqui apontados fomentam novas práticas e discussões em torno dos formatos de atividades para o ENCI.

\section{Metodologia}

Desenvolvemos um trabalho qualitativo, com caráter descritivo e propositivo, no qual se explicita elementos de conexão e ampliação das práticas de ENCI a partir da incorporação de elementos do Design, na busca de novos potenciais metodológicos.

Para um primeiro mapeamento dessas possibilidades de parceria do ENCI com o Design, partimos da descrição de metodologias já influenciadas pelo Design com bons resultados, buscando possibilidades de articulação. Fizemos um levantamento bibliográfico que envolveu a leitura de 78 artigos e livros, sobre os temas "Ensino de Ciências Por Investigação", "Ensino por Investigação", "Aprendizagem Baseada em Problemas", "Aprendizagem Baseada em Projetos", "Educação Através do Design", e outros temas e termos correlatos, nas principais bases de dados.

A partir dos elementos e possibilidades apresentadas por essas metodologias, apresentamos uma nova abordagem para o ENCI, que tem como foco a recursividade e a iteração dos processos de investigação e criação.

Assim, o sentido do projeto cria e investiga, investiga e cria, sempre nesse movimento de aprimoramento, tanto dos modelos teóricos ou experimentais como dos artefatos construídos ou experimentados nos processos, tecendo uma proposta que denominamos como Ensino de Ciências por Projeto Investigativo (ENCIPI). 


\section{Algumas Influências}

As transposições aqui dispostas estão focadas no conteúdo necessário para compreensão das questões básicas que distinguem cada abordagem, sem abordar seu percurso histórico.

Trazemos como influências a Aprendizagem Baseada em Projetos (Project-Based Learning - $\mathrm{PjBL}$ ), Aprendizagem Baseada em Problemas (Problem-Based Learning - PBL), Design Science (Ciência do Projeto ou do Artificial - DS/DSR), Design-Based Learning (DBL, Aprendizagem Baseada em Design), Design-Based Teaching (DBT, Ensino Baseado em Design) e a Educação Através do Design (EdaDe).

As abreviações foram adotadas conforme convenções (Oguz-unver, A. Arabacığlu, 2014), para as duas formas de PBL (Project e Problem-Based Learning), ou conforme recomendações dos próprios autores das abordagens, como para a Educação através do Design (EdaDe).

\section{Aprendizagem Baseada em Projetos (PjBL)}

A Aprendizagem Baseada em Projetos ( $\mathrm{PjBL}$ ), é uma modalidade de aprendizagem ativa e colaborativa, com adoção de temas transversais e interdisciplinares.

Consiste em um método sistemático de ensino que envolve os alunos através de um extenso processo de investigação estruturado em torno de questões complexas e autênticas e de produtos e tarefas (Buck Institute for Education, 2008, p. 18).

Bacich e Moran (2018, p. 17) apresentam quatro tipologias de projeto, e sua adoção está sujeita ao perfil dos alunos e objetivos do docente. Para esses autores, há: exercícioprojeto, componente-projeto, abordagem-projeto e currículo-projeto.

Os mesmos autores apresentam, também, que os projetos podem ser classificados conforme seus objetivos: explicativo, investigativo e construtivo (Bacich, \& Moran, 2018, p. 17):

- Projeto construtivo: quando a finalidade é construir algo novo, criativo, no processo e/ou no resultado.

- Projeto investigativo: quando o foco é pesquisar uma questão ou situação, utilizando técnicas de pesquisa científica.

- Projeto explicativo: quando procura responder questões do tipo: "Como funciona? Para que serve? Como foi construído?”. Esse tipo de projeto busca explicar, ilustrar, revelar os princípios científicos de funcionamento de objetos, mecanismos ou sistemas, por exemplo.

Embora haja a especificação dos projetos de tipo investigativo, este não é influenciado pelo Design, tal como este artigo propõe.

$\mathrm{Na}$ Aprendizagem Baseada em Projetos (Buck Institute for Education, 2008) os alunos confrontam-se com situações e contextos ambíguos, complexos e imprevisíveis, desenvolvem trabalhos de pesquisa e deparam-se com obstáculos, procuram recursos e resolvem problemas em resposta a um desafio. Estabelecem as suas próprias relações 
entre ideias e adquirem novas competências à medida que trabalham em diferentes tarefas.

Ao longo do processo, os alunos geram produtos intelectuais que demonstram a sua aprendizagem, como modelos, relatórios, esquemas, etc. e participam de sua própria avaliação.

Nessa perspectiva, os alunos desenvolvem-se emáreas muitas vezes negligenciadas, importantes para o mundo real, como competências sociais, de autogestão, autonomia, empatia, etc. Além disso, ela pode ir ao encontro de diferentes formas de aprendizagem demandada por alunos, de pesquisas individuais a trabalhos em grupo e discussões; fornece aos pais informações relevantes acerca dos diversos tipos de desempenho dos alunos, estabelece um clima não competitivo em sala de aula, e pode envolver alunos que normalmente não participam, além da articular objetivos cognitivos, sociais, emocionais, etc. (Buck Institute for Education, 2008).

\section{Aprendizagem Baseada em Problemas (PBL)}

A PBL, assim como a Aprendizagem Baseada em Projetos (PjBL) é uma proposta pedagógica que consiste no ensino centrado no estudante e é baseada na solução de problemas. O currículo dos cursos que utilizam PBL geralmente é dividido em módulos ou unidades temáticas, que são compostos de várias sessões e integram diversas disciplinas (Borges et al., 2014).

A PBL apresenta problemáticas, que devem ser resolvidas ou respondidas pelos estudantes. Entretanto, os problemas podem ser - inclusive - artificiais, com situações hipotéticas, e nem sempre relacionadas ao contexto dos envolvidos, embora notemos que há a preocupação da relevância, como forma de manter o engajamento dos alunos (Salvador et al., 2014).

Para solucionar o problema proposto, os alunos recorrem aos conhecimentos prévios, discutem, estudam, adquirem e integram os novos conhecimentos (Borges et al., 2014).

Salvador e colaboradores (2014) descrevem a realização de uma feira de ciências cujos projetos baseavam-se na lógica da PBL, após os professores terem participado de uma formação sobre essa metodologia. $\mathrm{O}$ interessante nesse caso foi a possibilidade do uso de uma metodologia focada na resolução de problemas (PBL), sendo utilizada para desenvolver projetos para a feira de ciências. Assim, pontuamos que existem práticas que utilizam a Aprendizagem Baseada em Problemas para desenvolver projetos, assim como práticas que utilizam e encaram a Aprendizagem Baseada em Projetos como possibilidade para resolução de problemas. O que muda ao utilizar uma ou outra metodologia é o foco dado a cada etapa, a autonomia e tipos de ação dos alunos, assim como o papel desempenhado pelo professor.

Dependendo do planejamento da PBL, pode-se ter a presença de tutores para acompanhamentos do grupo, assim como a organização de cargos entre os participantes de cada grupo (Borges et al., 2014). 
A PBL tem sido bastante utilizada no ensino de disciplinas da área de saúde, tendo como fontes de informação pacientes reais, pacientes simulados, exames laboratoriais, vídeos, textos de jornal ou revistas, fotos, artigos científicos, entre outras (Borges et al., 2014). Acreditamos que isso se deva ao caráter de diagnóstico, prescrição ou proposição dessas áreas.

As duas metodologias citadas (PjBL e PBL) indicam ações pedagógicas voltadas à solução de problemas. Essas metodologias podem ter, em comum, uma necessidade humana como ponto de partida.

"Elas se diferenciam em função da ênfase dada numa ou noutra fase ou atividade envolvida. Assim, o Método dos Projetos, favorece a identificação de problemas sociais, a reflexão sobre eles e a sua discussão." [...] "A ênfase do design, quando aplicado como método de ensino, está na solução de problemas com a realização de projetos, modelos, protótipos ou ainda dos próprios objetos ou sistemas. Resolver um problema de design, sentido como seu, é para a criança e para o jovem um desafio, logo uma motivação para entrar em atividade." (Fontoura, 2002, p. 132).

Fontoura pontua que a Aprendizagem Baseada em Problemas tem um caráter mais teórico e menos prático, o que não distancia a metodologia da realidade se os problemas propostos forem bem estruturados e passíveis de serem reais ou mesmo cotidianos para os alunos.

Acreditamos que é necessário criar formas de envolver os alunos e mobilizá-los para que consigam resolver questões específicas de maior ou menos complexidade. Para uma boa prática de Aprendizagem por Resolução de Problemas, recomendamos que o professor nunca mantenha foco na resolução em si, tratando-a como uma variável binária de "conseguir" ou "não conseguir". O percurso sempre é rico, e diferentes trilhas podem ser seguidas até que se atinja a resolução dos problemas.

\section{Design Science (DS) e Design Science Research (DSR)}

Esta influência não é uma metodologia ou abordagem pedagógica, mas sim um paradigma científico. O conceito da Design Science foi introduzido por Herbert Alexander Simon, no livro "As ciências do artificial" (Simon, 1996). Ela difere das ciências naturais e sociais, mas considera, em suas construções, os aspectos naturais e sociais envolvidos, o que favorece seu uso em sala de aula para situações que precisem ir além do que é somente natural ou social. A Design Science sempre tem um olhar de integração e complexidade.

A Design Science Research (metodologia para operar a Design Science) tem ganhado espaço por se dedicar à concepção e/ou ao estudo de artefatos. Ela tem como uma das principais características o rigor (evidenciado por meio de extensas revisões bibliográficas, testes e registros) e sobretudo a aplicabilidade prática do que foi construído, preocupando-se sempre com a relevância e as repercussões geradas.Um comparativo entre os três tipos de ciência pode ser visto na Figura 1.

A Design Science Research tem como propósito projetar e produzir sistemas que 
ainda não existem e modificar situações existentes para alcançar melhores resultados com foco na solução de problemas (Dresch et al., 2015). Assim, acreditamos que possa ser aproximada da educação, por possuir seu caráter criativo e crítico da realidade, atendando-se às necessidades latentes, aos conhecimentos disponíveis para a solução, aos impactos da alternativa escolhida, etc.

\begin{tabular}{|l|l|l|l|}
\hline Elemento & Ciências Naturais & Ciências Sociais & Design Science \\
\hline Propósito & $\begin{array}{l}\text { Entender fenômenos } \\
\text { complexos, descobrir } \\
\text { como as coisas são e } \\
\text { justificar o porquê de } \\
\text { serem dessa forma. }\end{array}$ & $\begin{array}{l}\text { Descrever, entender } \\
\text { e refletir sobre o } \\
\text { ser humano e suas } \\
\text { ações. }\end{array}$ & $\begin{array}{l}\text { Projetar e produzir sistemas que } \\
\text { ainda não existem e codificar } \\
\text { situações existentes para alcançar } \\
\text { melhores resultados com foco na } \\
\text { solução de problemas. }\end{array}$ \\
\hline $\begin{array}{l}\text { Objetivo da } \\
\text { pesquisa }\end{array}$ & $\begin{array}{l}\text { Explorar, descrever, } \\
\text { explicar e predizer. }\end{array}$ & $\begin{array}{l}\text { Explorar, descrever, } \\
\text { explicar e predizer. }\end{array}$ & $\begin{array}{l}\text { Prescrever. As pesquisas } \\
\text { são orientadas à solução de } \\
\text { problemas. }\end{array}$ \\
\hline $\begin{array}{l}\text { Principais áreas } \\
\text { que costumam } \\
\text { utilizar esse } \\
\text { paradigma } \\
\text { científico }\end{array}$ & $\begin{array}{l}\text { Física, Química e } \\
\text { Biologia. }\end{array}$ & $\begin{array}{l}\text { Antropologia, } \\
\text { Economia, Política, } \\
\text { Sociologia e } \\
\text { História. }\end{array}$ & Medicina, Engenharia e Gestão. \\
\hline
\end{tabular}

Figura 1. Propósitos, objetivos e áreas das ciências naturais, sociais e do projeto/artificial (Design Science).

Fonte: Dresch, Lacerda, e Júnior (2015, p. 15)

Outra característica é que, em vista do objetivo criativo, a Design Science trabalha, principalmente, com o raciocínio abdutivo (Dresch et al., 2015), que parte da adoção temporária de uma hipótese, sendo que suas consequências são passíveis de verificação experimental. Segundo Ramos (2016), a abdução propõe o que pode ser ao invés de "afirmar a partir do que é" (indução) ou "afirmar o que deve ser" (dedução). Para o mesmo autor, esse tipo de raciocínio pode ser considerado o início de todas as descobertas científicas, uma vez que a abdução possui um caráter intuitivo, em que prevalece a imaginação e especulação, dando espaço às vontades e experiências vividas pela mente especulativa, o que pode ser transposto de forma consciente aos processos de ensino de ciências.

\section{A Design-Based Learning (DBL)}

Retornando para as metodologias e abordagens didáticas, a Design-Based Learning (Nelson, 2009) tem como objetivo envolver os alunos em pensamentos mais complexos através da construção de artefatos físicos a partir dos conceitos desenvolvidos no currículo.

Antes de os alunos começarem a ler, escrever ou falar sobre o conteúdo, o professor apresenta o desafio. Nelson (2009) exemplifica: se a lição for sobre o transporte de bens e serviços, um exemplo de desafio pode projetar um sistema nunca antes visto para mover 
pessoas e produtos dentro de uma cidade. Isso envolve uma lista de especificações da solução, com o que ela deve ou não deve ter.

No Design Based Learning (DBL) elaborado por Nelson, os alunos começam projetando e construindo um objeto nunca antes visto que já sensibiliza para as competências a serem construídas durante o curso. Além de construir, os alunos precisam explicar como o objeto funciona e a qual contexto pertence e somente após esta sensibilização através do planejamento e construção ocorrem as aulas tradicionais para desenvolver os conhecimentos trabalhados naquele segmento. (Martins, \& Couto, 2016, p. 5, destaques do original).

Essa estrutura de construir para, em outro momento, ter aulas tradicionais a fim de "desenvolver os conhecimentos trabalhados" não será adotada por nós. Isso não significa que aulas tradicionais não serão desenvolvidas em nossa proposta, mas sim, que, da forma proposta pela DBL, grande parte do caráter autoral dos alunos é perdido, em um movimento explicativo.

\section{O Design-Based Teaching (DBT)}

Burnette (2005c) organiza algumas características de sua proposta: é focada em projetos que podem envolver vários assuntos e disciplinas, se concentra no que poderia ser e no que poderia funcionar para alcançar objetivos, incentiva os alunos a gerar e analisar suas próprias ideias, baseia-se na autoavaliação e reflexão para ajudar o aluno a avaliar seu próprio progresso e aprender com ele, enfatiza o desenvolvimento do conhecimento pelo aluno.

Além disso, na DBT o aluno desenvolve metas, informações, ideias e propostas de projeto e, em seguida, executa-as com o apoio do professor, participando ativamente de um projeto e trabalhando com outros para torná-lo bem-sucedido, apresentando e explicando suas ideias, compreendendo e interpretando o que os outros apresentam, etc.

A avaliação pode ser feita por rotinas de pensamento (intencional, referencial, relacional, etc.), como será descrito na seção "Possibilidades de Avaliação".

\section{Educação Através do Design (EdaDe)}

A Educação Através do Design (EdaDe) parte do princípio de que as crianças devem ser capazes de fazer, não só de pensar. Segundo Fontoura (2002), combinar pensamento e ação de maneira efetiva representa um dos principais objetivos da Educação através do Design.

Para o autor, em uma prática de educação alinhada ao Design, surgem duas grandes fases: uma conceitual e outra projetual que também podem ser denominadas, respectivamente, como análise e síntese. Estas duas principais fases podem ser subdivididas etapas, passos ou procedimentos. Entretanto, o autor não aponta modelos para serem seguidos, pois não considera a EdaDe como um método, mas como uma filosofia, uma concepção educacional, uma proposta pedagógica.

"AEdaDeentão,nãodeveserentendidacomoummétodopoiselanãoestabeleceumconjunto 
de regras fixas e precisas - padrão - que garantem aprendizados corretos e adequados, apesar de objetivá-los. Por mais que se queira, ela não garante uma ordem e um caminho único, geral e seguro para o trabalho docente pois trata-se de um meio aberto no qual se trabalha com incertezas e imprevisibilidade; e é acima de tudo, um processo não linear. Em parte, a proposta de EdaDe visa atuar no âmbito do currículo escolar e não apenas nas práticas isoladas das salas de aula - desenvolvimento de projetos ou solução de problemas" (Fontoura, 2002, p. 133).

Por fim, a EdaDe pode ser explorada através da inclusão de disciplinas no currículo relacionadas com o Design, ou ainda pela inclusão de temas a serem trabalhados de forma transversal no currículo. Poderia também ser explorada informalmente, através de programas complementares (Fontoura, 2002).

Essa é a proposta que mais nos influencia como filosofia, na estruturação do que propomos como Ensino de Ciências por Projeto Investigativo.

\section{Ensino de Ciências por Projeto Investigativo (ENCIPI)}

Escolhemos o nome Ensino de Ciências por Projeto Investigativo (ENCIPI) para essa abordagem, que possui influências explícitas do Design, por considerá-lo mais fiel à proposta desenvolvida. Com esse nome, parece haver maior foco no processo construtivo e investigativo de artefatos, teorias, conceitos, ações, etc. Temos então uma visão de Projeto como percurso, permeado por uma investigação.

Enfatizamos que essa visão projeto-investigativa ${ }^{6}$ se aproxima de um sentido de investigação que compartilhamos com Sasseron:

No dicionário, a palavra "investigação" aparece como sinônimo de pesquisa, de busca. Neste momento podemos começar a pensar no que seja a investigação científica. Esta sim é uma pesquisa, uma busca, mas, como muitas das experiências que temos em nossa vida, o mais importante da investigação não é seu fim, mas o caminho trilhado (Sasseron, 2013, p. 42).

Por isso, investigar não é uma ação restrita ao processo de elaboração de hipóteses, nem a atividades experimentais. Como pontuado por Sasseron, investigar é buscar.

Caminhando para os sinônimos da palavra "busca", destacamos as palavras "demanda" e "pretensão", por estarem tão próximas do Design. Todo design possui uma "demanda" e uma "pretensão". Portanto, uma busca, uma investigação. Sem uma busca, o Design seria um processo vazio e irrelevante: não seria Design.

O ENCIPI não é uma simples "mescla" do Ensino de Ciências por Investigação com alguma forma de aprendizagem por projetos. Isso porque as investigações, em geral, são desenvolvidas sem a construção de projetos, e os projetos, por sua vez, podem ser desenvolvidos sem ter clara influência do Design.

Entretanto, o contrário não é verdadeiro: nunca há Design sem projeto e sem

6 Utilizaremos "projeto-investigativo" como adjetivo, para, por exemplo, nos referirmos a uma abordagem "projeto-investigativa" quanto à sua natureza, e projeto investigativo (com espaço) como substantivo em relação ao que se desenvolve: um projeto investigativo. 
algum tipo de investigação. É preciso iterar, aprimorar. E isso muito tem em comum com a ciência, que não é estática. Design e Ciência sempre estão em movimento, possuem intencionalidade e visam atender a uma demanda.

Para que possamos avançar na descrição e proposição do ENCIPI, trazemos, de forma sintetizada, na Figura 2, uma organização dos principais pontos considerados de cada abordagem para a proposição de um Ensino de Ciências por Projeto Investigativo.

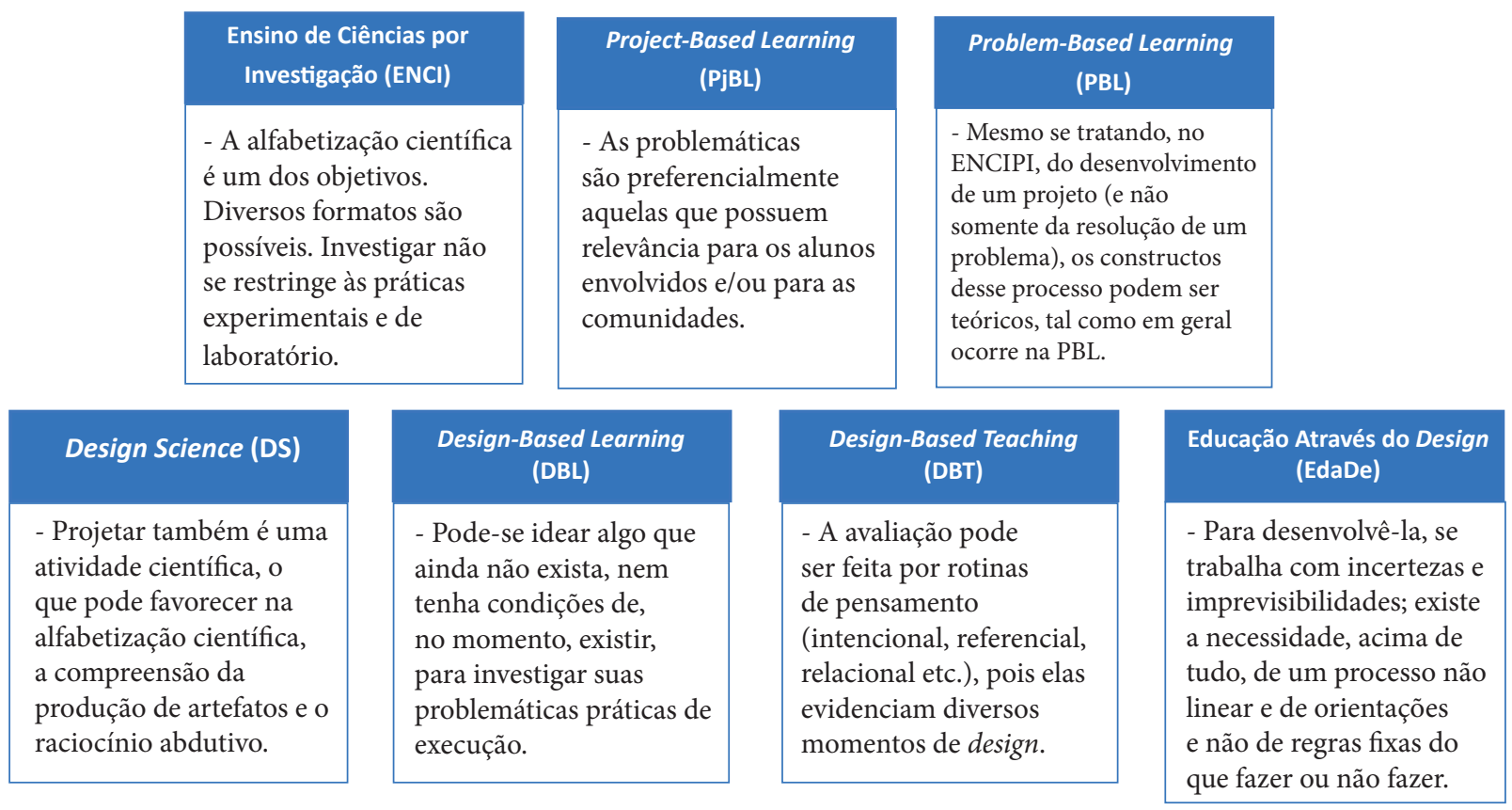

Figura 2. Principais influências de outras abordagens para o ENCIPI

Assumidos esses pontos, passamos para a descrição das ações envolvidas em um projeto investigativo.

Vale destacar que o ENCIPI, tal como descrito aqui, é a possibilidade de parceria entre elementos do Design com o ENCI, o que pode ser feito utilizando outros recursos, diferentes dos que aqui estão sendo apresentados.

\section{As Ações no ENCIPI}

Diversas ações podem ser desenvolvidas durante uma prática de ENCIPI. Não temos como objetivo padronizar, mas sugerir o formato da prática por acreditar que existam tanto demandas que exigem mais do que modelos prontos, como por ver, também, na diversidade de práticas, uma riqueza para que surjam novas discussões e propostas.

De forma resumida, sugerimos para o ENCIPI seis momentos: (1) estabelecer e programar; (2) expandir e aproximar; (3) propor; (4) criar; (5) validar e aprimorar; (6) comunicar, implementar e aprender.

Organizamos, neste trabalho, a apresentação dessas seis etapas em três frentes: ações dos estudantes; ações do professor; e recursos e ferramentas das ações. 
As duas primeiras frentes correspondem a algumas ações recomendadas para cada uma das etapas, para alunos (na Figura 3) e professores (Figura 4). Enfatizamos que esse percurso não é linear. Novas ações podem surgir, variando conforme o tipo de projeto em desenvolvimento e a intencionalidade pedagógica por trás do projeto investigativo.
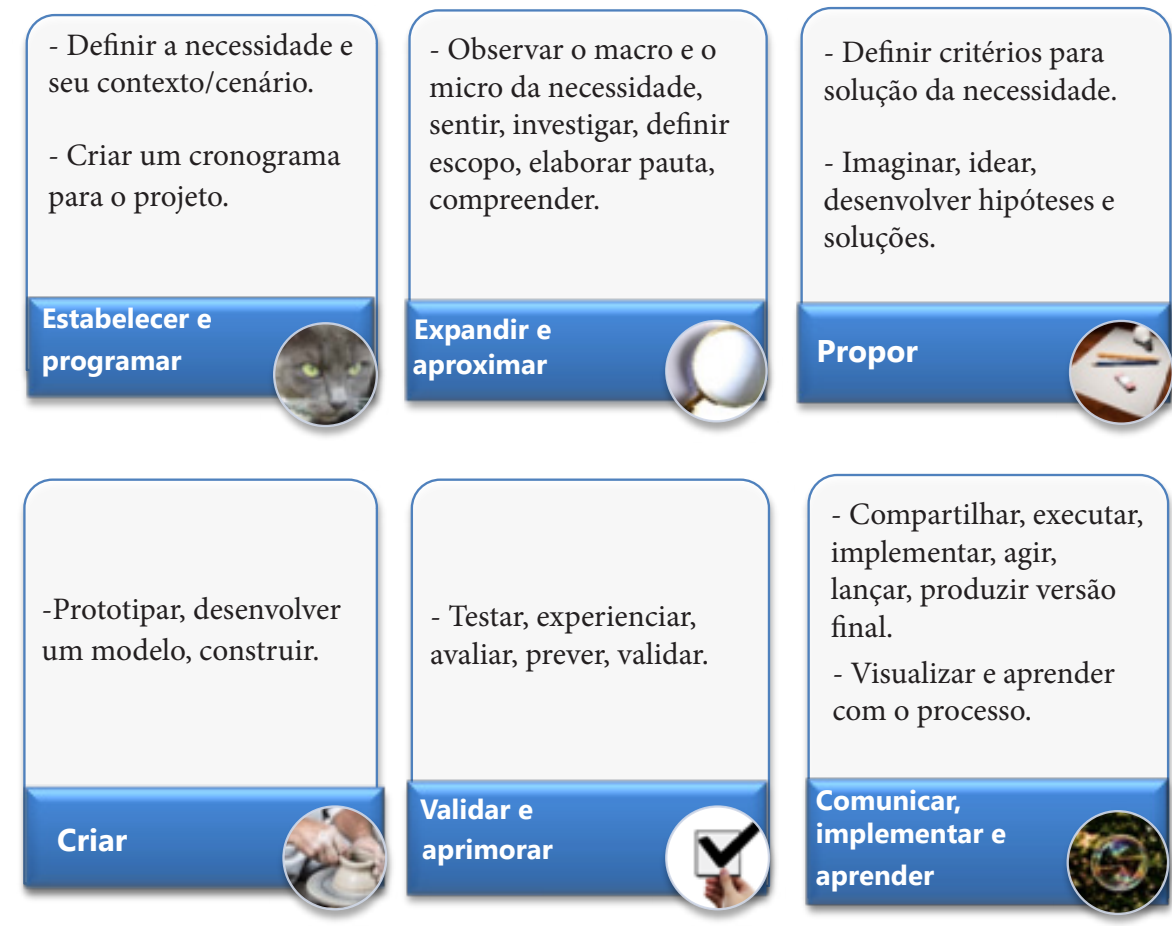

Figura 3. Ações dos estudantes em cada uma das etapas do ENCIPI

Apresentamos uma síntese para cada momento:

1. Estabelecer e programar: O primeiro momento, de estabelecer e programar, serve para identificar e definir qual necessidade será trabalhada durante o projeto.

Acreditemos que quanto maior a liberdade e autonomia dos alunos, desde a escolha da temática até a avaliação, melhor será para o desenvolvimento do projeto e para o aprendizado dos alunos (para sua motivação, autonomia, protagonismo, etc.). Caso os professores e alunos não possuam experiências no desenvolvimento de projetos, o professor pode iniciar a prática de ENCIPI com maior influência no processo, aumentando a liberdade dos alunos conforme aumenta a confiança de ambos em si e nesse tipo de prática.

O professor pode, por exemplo, definir o tema "gravidez" ou "anticoncepcionais" de forma ampla e propor que os alunos levantem uma necessidade que considerem relevante, ou delinear mais: Como desenvolver, para mulheres, um anticoncepcional que não agrida seu organismo? .

\footnotetext{
7 Este exemplo de necessidade será utilizado neste artigo para ilustrar o que ocorre em cada etapa.
} 
A partir disso, tendo estabelecido a necessidade, os alunos mapeiam o contexto, que, para o exemplo, engloba todas as mulheres, no mundo inteiro, que usam anticoncepcionais, as que não usam devido aos efeitos prejudiciais ao organismo, as que não usam por restrições de saúde, etc.

Para exemplificar outras necessidades para abordagem projeto-investigativa, trazemos uma pesquisa breve sobre a produção da Feira Brasileira de Ciências e Engenharia (FEBRACE, n.d.). Uma característica dessa feira é que os projetos são desenvolvidos somente por estudantes de educação básica, orientados por um professororientador.

Partindo de cinco anos de anais FEBRACE para a área de Biologia, utilizamos o software FromText ${ }^{8}$ para buscar palavras que demonstrassem a ideia de público ou contexto para as soluções desenvolvidas por esses projetos (como "cidade", "município", "escola", etc.). O objetivo foi levantar alguns exemplos de trabalhos que saíssem de uma lógica fenomenológica e abordassem um problema entendido como relevante para os alunos e sua comunidade.

Encontramos trabalhos que discutem possíveis soluções para o controle da alta proliferação de caramujos em uma cidade, avaliam as condições sanitárias de alfaces em feiras livres, trabalham a reciclagem de óleo, desenvolvem formas de captação de lixo orgânico, exploram o potencial turístico marinho de uma cidade, desenvolvem um forno solar, estudam o potencial medicinal de uma planta típica brasileira para diabetes ou o potencial antibiótico das sementes de mamão, a dessalinização da água, o desperdício de alimentos, o potencial de revitalização de um terreno, entre outros.

Esses projetos exemplificam algumas problemáticas com valor contextual para os estudantes (ou que eles compreendam ser de interesse e relevância pública). Esses temas (como o controle sanitário de alimentos, a preocupação com a diabetes, a reciclagem de óleo, o desenvolvimento de um forno solar, etc.) nos lembram os Objetivos de Desenvolvimento Sustentável, assim como os Desafios do Milênio da Organização das Nações Unidades (2017), que podem servir de base para a elaboração de propostas de investigação considerando a perspectiva biológica desses diversos desafios.

Nesta primeira etapa, ao definir uma necessidade e seu contexto, os alunos podem iniciar a elaboração de uma pauta de design ${ }^{9}$, que será continuada nas próximas etapas. A pauta de design, ou design brief, é uma espécie de "contrato", que traz as especificações do que deve ser atendido. Ela é uma especificação mais precisa da necessidade, e como, de forma ampla, pode ser superada através do projeto.

8 Trata-se de um software de apoio à pesquisa qualitativa, desenvolvido pelo primeiro autor deste trabalho, com objetivo de facilitar a visualização de elementos presentes no texto, e que teve como influência a Teoria Ator-Rede (Latour, 2012) durante seu desenvolvimento. Mais informações podem ser vistas em www.fromtext.net.

9 A partir desta etapa, pode-se utilizar alguns recursos como Canvas (um tipo de estrutura a ser preenchida para se ter uma melhor visualização da questão que está sendo trabalhada), e modelos de pauta de design. Estamos trabalhando na construção de recursos de apoio para ENCIPI, que serão disponibilizados no endereço www. gsbruno.com/encipi 
2. Expandir e aproximar: A segunda etapa, de expansão e aproximação, envolve o pesquisar. É a etapa que começa a se delimitar melhor a pesquisa. Neste momento, os alunos precisam desenvolver ações como observar, sentir e investigar, para então compreender melhor a necessidade/problema e definir precisamente o escopo do projeto, continuando a elaboração de sua pauta de design.

Retornando a necessidade "Como desenvolver, para mulheres, um anticoncepcional que não agrida seu organismo?", os alunos podem iniciar a etapa de "expandir e aproximar" partindo de um segundo olhar sobre o próprio contexto definido, visualizando urgência de se pensar novas soluções, sem se esquecer das pessoas envolvidas na necessidade (neste caso, as pessoas compõem o macro da necessidade). O "micro" dessa necessidade são as partes que influem no macro: a própria composição química e as reações biológicas dos anticoncepcionais. É um momento para encarar o desafio, compreender suas correlações e tê-lo como relevante, desafiador e motivador.

Embora seja essa uma etapa de investigação, a pesquisa e a descoberta ocorrem durante todo o percurso, pois, para propor, criar, validar e implementar é necessário se apropriar de conhecimentos.

3. Propor: Define-se um foco, que pode ser, às vezes, bastante parecido com o título da própria necessidade, ou algo mais específico, como, referente ao exemplo do anticoncepcional: pensar possibilidades anticoncepcionais masculinas ou somente possibilidades não hormonais para mulheres.

O foco pode ser estabelecido somente após um primeiro brainstorming. Este é um momento de bastante criatividade, e é preciso que todos estejam alinhados à ideia e consigam, em menor ou maior complexidade, visualizar que é possível chegar à solução, e de que forma a ideia proposta soluciona a necessidade.

4. Criar: É possível desenvolver um primeiro modelo ou protótipo para a solução? Se a questão for somente teórica, esse é o momento de desenvolver melhor as hipóteses existentes. Este é um momento de criação de uma versão prévia, que deve anteceder a versão final da solução.

Para nosso exemplo, este seria o momento de descrever as primeiras e principais características necessárias para uma solução que possa ser desenvolvida no futuro. Ou seja: a especificação do funcionamento de um anticoncepcional que não agrida ao organismo.

Enfatizamos que se trata de um exemplo de solução, uma vez que, para um mesmo desafio, um projeto sempre assume rumos diferentes, que se apoiam nos conhecimentos prévios de quem os desenvolve, e mesmo no que é possível desenvolver.

5. Validar e aprimorar: É possível testar a solução de maneira prática? Se não for, é possível prever se ela atenderá de fato a necessidade? Como evidenciar se a solução cumpre aos requisitos?

Os alunos precisam conseguir avaliar a proposta em construção e, sobretudo, aprimorá-la, reconhecendo neste momento o que é necessário para que a solução 
cumpra as expectativas descritas na pauta de design.

Este é, de fato, um dos momentos mais importantes desde o início da construção do projeto. Isso porque, mais do que construir, é preciso julgar suas construções, utilizando para isso metodologias e recursos adequados.

6. Comunicar, implementar e aprender: Este é o momento de comunicar a solução para os colegas de turma, para outras séries, para a comunidade ou para o mundo, e possibilita que os alunos exercitem a argumentação e consigam posicionar-se e defender a solução criada, obtendo novos feedbacks, conhecendo outros pontos de vista e sendo parabenizados por seu projeto e sua trajetória.

Uma possibilidade, quando na finalização dos projetos, é a construção de uma feira de ciências ${ }^{10}$ na escola, para que os alunos apresentem seus trabalhos de forma bimestral, semestral ou anual, o que cria na escola uma cultura investigativa e integrativa. Isso pode facilitar a inclusão do ENCIPI na rotina da escola, e possibilitar que esses projetos sejam desenvolvidos por maior tempo.

Além de comunicar, implementar a solução, quando possível, é uma etapa de concretização. Se os alunos escolherem propor uma mudança na legislação nacional sobre anticoncepcionais, por exemplo, implementar pode ser fazer ampla divulgação da proposta e recolher assinaturas para enviá-las à Câmara dos Deputados. É o momento em que a solução ganha vida.

Esta também é uma etapa para visualizar o processo completo, repensando outras possibilidades para o projeto, reconhecendo pontos de falha, ou definindo possíveis continuidades para a solução.

Pontuadas as principais ações dos alunos e algumas recomendações de ações para os professores, sintetizamos na Figura 4, as principais ações do docente durante o projeto.

Além de desempenhar suas ações (pontuadas na Figura 4) e orientar as ações dos alunos (Figura 3), o professor pode, para cada etapa, especificar com maior precisão as competências e habilidades que serão desenvolvidas. Por exemplo: reconhecer a importância de novos métodos contraceptivos em todo o mundo (na etapa "estabelecer e programar"), compreender os efeitos químicos e biológicos de anticoncepcionais tradicionais no corpo feminino (na etapa "expandir e aproximar"), compreender como ocorre a gravidez desde o nível molecular (ainda na etapa "Expandir e aproximar"), etc.

Para possibilitar que os alunos tenham liberdade e autonomia durante o desenvolvimento do projeto, é necessário grande empenho do professor nos "bastidores" do mesmo. É preciso que o professor visualize, de forma antecipada, o percurso que está sendo trilhado, para que não se perca nenhum objetivo pedagógico por trás do projeto.

10 A APICE (FEBRACE \& Intel, 2018) oferece cursos que podem auxiliar no desenvolvimento de projetos (para professores e alunos), assim como para organização desse tipo de evento. A quem interessar, sugerimos que acesse o material na íntegra. 

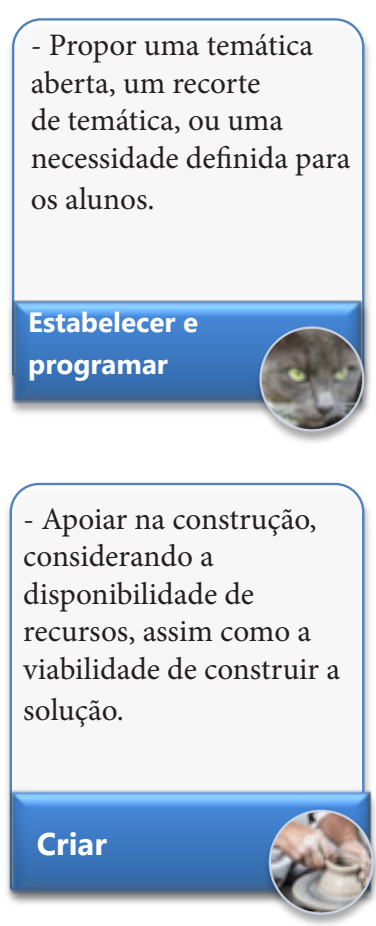

- Orientar o início do projeto, fomentar discussões, guiar o aprofundamento com base nas primeiras ideias, guiar estudos autônomos, esclarescer dúvidas, etc.

\section{Expandire} aproximar

- Apoiar na escolha do
método de validação,
auxiliar na conferência
dos critérios, prestar
feedbecks, acompanhar
teste e aprimoramento da
solução.
Validar e
aprimorar

- Interferir ou não, conforme a intencionalidade, auxiliando na construção e/ou escolha da(s) ideia(s).

- Propor ajustes no cronograma de trabalho.

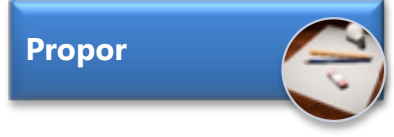

- Providenciar parcerias, auxiliar na divulgação e/ou implementação do projeto. Guiar uma visualização do percurso, fazendo considerações sobre cada etapa do projeto.

Comunicar,

implementar e aprender

Figura 4. Principais ações do professor em cada uma das etapas do ENCIPI

Para o ENCI, Almeida e Sasseron (2013) apresentam, para o planejamento, a possibilidade de se pensar: (a) ideias sobre o planejamento das atividades; (b) ideias para orientação dos alunos em sala de aula; (c) ideias estruturais; (d) ideias de avaliação sobre a construção de conhecimentos dos alunos e (e) ideias de avaliação reflexiva sobre a prática docente.

As "ideias balizadoras para planejar uma sequência de ensino investigativa", apresentadas no parágrafo acima, podem contribuir na tentativa de se prever, durante os planejamentos, possíveis interações entre o professor-alunos, inquietações, perguntas e desafios que podem surgir ao longo do projeto, para que o professor possa guiar as atividades com maior propriedade, sabendo reagir melhor às situações que foram previstas.

No desenvolvimento das atividades, a formulação de perguntas, por parte do professor, é essencial na provocação dos alunos, e a sua boa utilização depende da habilidade do professor de saber escolhê-las e formulá-las ${ }^{11}$ de forma clara e precisa, de saber criar oportunidades para que as crianças também perguntem (Fontoura, 2002). Provocar não é somente propor para os alunos uma tarefa ou questão desafiadora. Para que os alunos a considerem como uma provocação é necessário que se sintam encorajados e potentes diante do desafio.

11 As perguntas podem ser: estimuladoras: aquelas que levam às descobertas; reforçadoras: para avaliar até que ponto o ensino-aprendizagem decorreu com eficiência; esclarecedoras: com a intenção de fornecer ou trazer mais informações; divergentes: que estimulam o pensamento criativo, permitindo diferentes respostas; e convergentes: solicitam uma única resposta, isto é, são unidirecionais (Mansur \& Moretto, 2000, citado por Fontoura, 2002). 
Uma vantagem desse tipo de trabalho é que os projetos sempre serão conduzidos de forma correspondente ao contexto, vivência e repertório dos alunos. Assim, turmas de diferentes idades devem propor respostas diferentes à temática, com níveis de aprofundamento diferentes.

O professor precisa definir de que forma e quando irá intervir. Diversos erros conceituais vão surgir, e serão corrigidos, junto aos alunos. $\mathrm{O}$ importante aqui é permitir que eles expressem o que já sabem, e ir aprofundando em conjunto o que se sabe.

É importante saber lidar como erros e reajustes. Isso também permite que eles próprios tenham noção da complexidade da problemática escolhida e consigam repensar, a partir de então, outras formas de solução.

Caso haja necessidade, é possível parar um projeto para um momento de exposição do professor, como uma forma de aprofundamento. Mas é melhor que isso ocorra após os estudantes perceberem a necessidade (se houver).

De forma semelhante, conteúdos obrigatórios que não forem abordados durante o projeto, podem ser trabalhados ao final, por exemplo, sob a forma de aprofundamento, estabelecendo como aquele conhecimento poderia ter contribuído para solução da necessidade, ou, preferencialmente, através do início de um novo projeto sobre o mesmo ou outro tema.

Retomando situações-problemas que podem não ser experimentais, uma possibilidade de projeto investigativo é trabalhar a construção de outros tipos de produto. Um exemplo: Existe alguma exposição sobre evolução na cidade? Se sim, como propor uma nova, com base em pontos da exposição existente? Se não: é possível criar uma exposição e propor para um museu local?

Outra possibilidade seria propor que os alunos construam um E-book para ser publicado na internet com o tema: Para onde caminha a evolução?

A disponibilidade de recursos é um elemento que será considerado, e é interessante perceber como os alunos adaptam a rota do projeto através dessas considerações. É preciso aprender a criar, mesmo com recursos limitados, desenvolvendo soluções inovadores para isso.

Outro exemplo de necessidade: Diminuir o desmatamento.

Os alunos poderão criar um projeto de área de proteção permanente, um tipo de plástico, uma madeira transgênica de rápido crescimento, uma proposta de ONG de reflorestamento, ou algo mais simples, como uma conscientização da comunidade sobre a importância da pauta desmatamento, por exemplo, sem nunca esquecer: quais são as repercussões e o que está envolvido nessa solução?

$\mathrm{Na}$ integração com outras disciplinas, partindo desse exemplo, poderíamos abordar as propriedades dos diferentes materiais: a madeira poderia ser substituída 
por plástico? Mas o que é a madeira e o que é o plástico? Como calcular uma área de proteção? O raio de uma nascente? O tempo de reflorestamento de uma área?

Mais uma possibilidade de projeto investigativo seria alimentar uma seção sobre desmatamento na Wikipédia. Esse tipo de projeto envolve reconhecer erros e informações incompletas ou ambíguas no material já existente na Wikipédia, e propor novos textos, que serão revisados pelo professor. Os alunos percebem a necessidade e seu público, desenvolvem olhar crítico ao conteúdo/produto existente, aprofundam seu conhecimento sobre a temática, desenvolvem, melhoram e implementam o texto na plataforma, dando visibilidade ao que foi produzido para o mundo inteiro.

As ações, em qualquer etapa, demandam recursos e ferramentas que foram organizadas na Figura 5. Novamente, fizemos o possível para que fossem abrangentes, sendo necessário que professor e aluno decidam quais recursos serão utilizados.
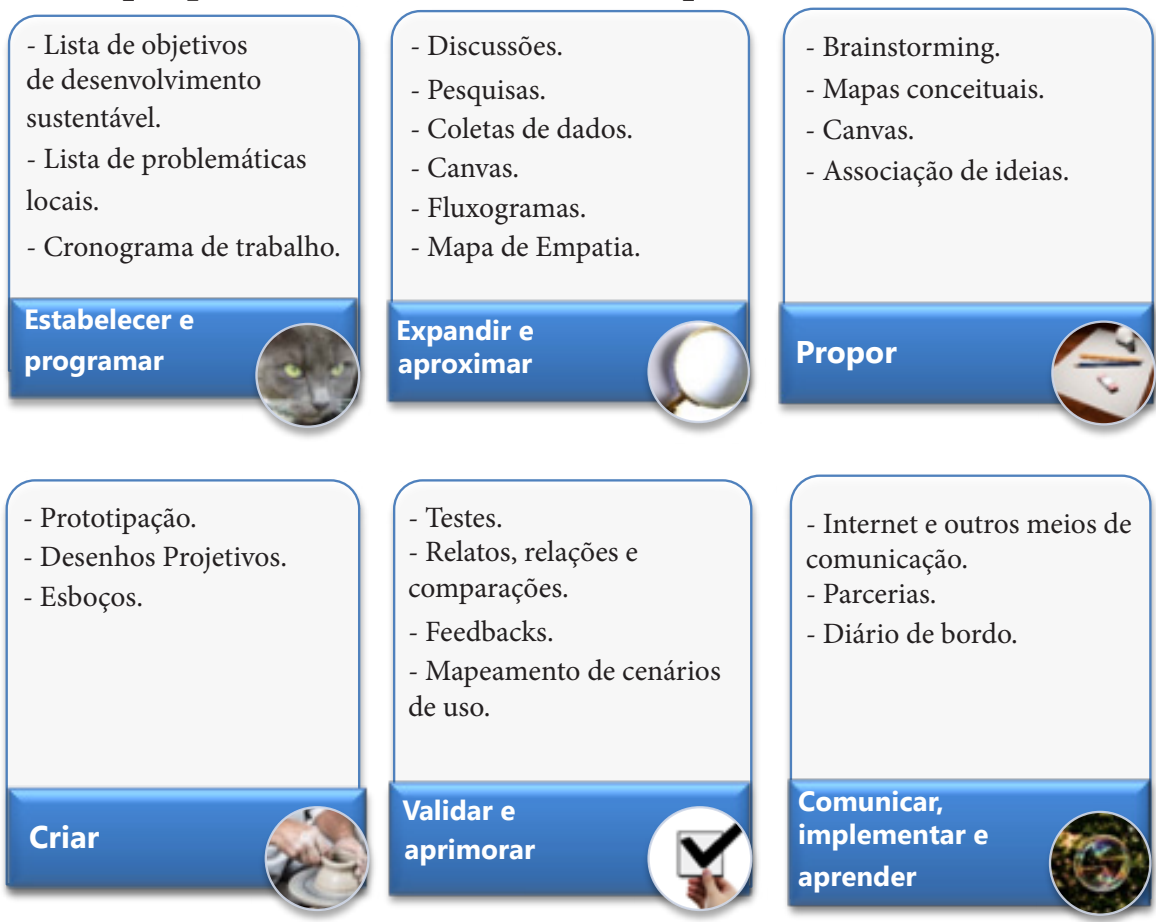

Figura 5. Principais recursos e ferramentas envolvidas em cada uma das etapas do ENCIPI

Mas somente os recursos não fazem o Design. É preciso propor ações e estimular seu uso sem apresenta-los de forma fechada. O Design é sempre mais do que seus elementos: é também repensar (e até desenhar) os melhores recursos e ferramentas de acordo com as demandas que emergem durante o desenvolvimento do projeto.

\section{Possibilidades de Avaliação no ENCIPI}

Em diversos momentos deste trabalho, enfatizamos que tanto o Design como a educação valorizam intensamente o processo. Assim, uma parte considerável das avaliações pelo ENCIPI pode ser feita não apenas pelos resultados ou produtos gerados, mas pelo percurso: 
Criar o hábito de tomar notas, fazer observações, fazer esboços, fazer comentários, relatar atividades, desenhar, anotar as dúvidas, fazer esquemas, enfim, "registrar no papel" e falar sobre o que foi feito, se está fazendo e sobre o que será feito, são valiosos recursos que auxiliam o aprendizado e, apesar de aparentemente caóticos, desenvolvem um senso de organização no educando. Este hábito pode ser desenvolvido com as crianças desde os primeiros anos de escolaridade (Fontoura, 2002, p. 207).

Tudo isso pode ser utilizado nas avaliações, criando indicadores para tal, que podem (ou devem) ser compartilhados com os alunos, tornando a avaliação um processo formativo no qual os alunos tenham maior consciência do que estão desenvolvendo e de que forma podem melhorar.

Por um viés profissional no Design, em geral, a avaliação é feita com base no grau de sucesso do projeto construído, levando em consideração os requisitos estabelecidos na pauta de design (sendo diversas vezes necessário o retorno à fase de desenvolvimento). Para Fontoura (2002), em um contexto com intencionalidade pedagógica, "mais importante que aprender a avaliar a solução do problema em si, é fazer com que as crianças verifiquem e dimensionem o que aprenderam e como aprenderam" (p. 193).

Burnette (2005b) desenvolveu algumas questões avaliativas que visam identificar o avanço do aluno em alguns tipos de pensamento:

1. Pensamento Intencional: Por que você está fazendo isso?

2. Pensamento Referencial: Como você descreveria isso?

3. Pensamento Relacional: Por que essa é uma boa ideia?

4. Pensamento Formativo: Você pode explicar isso para mim?

5. Pensamento Processual: Como você faz isso?

6. Pensamento Avaliativo: Como você sabe disso?

7. Pensamento Reflexivo: O que você lembra?

Tais questões podem fazer com que o aluno consiga visualizar o resultado de seus avanços em cada questão, tornando-se mais consciente ${ }^{12}$ sobre o processo e mais crítico sobre seu desenvolvimento. Vale destacar que diversos desses momentos de aprendizagem são marcados por interações discursivas, que podem ser exploradas para identificar em que pontos os alunos já se apropriaram e quais demandam novos reforços (Camargo, Motokane, \& Castro, 2016; Sasseron, 2013).

12 De forma semelhante, para crianças mais novas, Fontoura apresenta a possibilidade de fotografar as crianças enquanto executam as atividades e num momento posterior, diante das imagens, questioná-las sobre o que estavam e, por que estavam fazendo aquilo naquele instante, criando uma retrospectiva das atividades desenvolvidas e estabelecendo as conexões entre elas. Para mais detalhes, ver Fontoura (2002) p. 193. 


\section{Alguns Desafios}

Sobre os desafios que podem ser encontrados em uma prática que se oriente pelo ENCIPI, acreditamos que eles sejam também compartilhados por outras metodologias. São eles:

- A quebra da passividade dos estudantes pode gerar desconforto por exigir uma postura ativa que não é sempre bem aceita por todos os estudantes. (Borges et al., 2014)

- O tempo para realização das atividades é maior do que o normalmente utilizado em aulas tradicionais (Moreira et al., 2014).

- O professor, deve portar-se como mediador do processo, o que pode demandar um treinamento prévio (Fontoura, 2002; Moreira et al., 2014).

- Os projetos podem exigir recursos para serem realizados (materiais, equipamentos, ferramentas, e, por vezes, instalações), o que demanda investimentos (Fontoura, 2002; Moreira et al., 2014).

- Pode haver demanda de um trabalho de divulgação e de esclarecimento das finalidades, objetivos e benefícios, junto à comunidade (escola, família, alunato, sociedade em geral) sobre a abordagem utilizada (Fontoura, 2002).

- O planejamento deve ocorrer considerando as possibilidades cabíveis de cada cenário. O ENCIPI pode estar alinhado a uma atividade simples e reduzida em uma disciplina, de forma ampliada e semestral ou ainda em parceria com outras disciplinas (o que envolve uma maior articulação e uma possível necessidade de que as outras disciplinas também se alinhem ao Design).

\section{Conclusões}

$\mathrm{Na}$ busca de novos potenciais metodológicos para o ensino de ciências, o alinhamento do ENCI ao Design é coerente na medida que consideramos ambos como processos construtivos e simultaneamente investigativos.

Fizemos um levantamento bibliográfico que envolveu a leitura de artigos e livros sobre os temas "Ensino de Ciências por Investigação", "Aprendizagem Baseada em Problemas", "Aprendizagem Baseada em Projetos", "Educação Através do Design”, e outros temas e termos correlatos.

A partir dos elementos e possibilidades apresentadas por essas metodologias, apresentamos uma nova abordagem para o ENCI, que tem como foco a recursividade e a iteração dos processos de investigação e criação, tecendo uma proposta que denominamos como Ensino de Ciências por Projeto Investigativo (ENCIPI).

Para o ENCIPI, definimos seis etapas para o desenvolvimento de projetos investigativos: (1) estabelecer e programar; (2) expandir e aproximar; (3) propor; (4) criar; (5) validar e aprimorar; (6) comunicar, implementar e aprender, e orientamos os 
principais movimentos de cada etapa, para professores e alunos, assim como os recursos envolvidos para as mesmas.

Quanto às formas de condução das atividades, referente ao número de alunos por grupo, a duração dos projetos, as formas de avaliação, entre outros pontos, acreditamos que os professores devem seguir o que for adequado ao cenário, assim como em qualquer metodologia ativa, considerando as limitações existentes e suas possibilidades de superação.

Mesmo que os alunos tenham grande liberdade no processo, o professor é sempre um ator insubstituível, que não age apenas como problematizador, mas que define e alcança objetivos pedagógicos profundos a partir dessa liberdade.

Materiais de apoio e outros trabalhos estão sendo desenvolvidos, a fim de apoiar e subsidiar práticas de Ensino de Ciências por Projeto Investigativo, e poderão ser acompanhados em www.gsbruno.com.br/encipi.

Acreditamos que a articulação proposta abre espaço para novas discussões que surgem da intersecção entre as duas áreas tão ricas para a Educação, no que se refere ao desenvolvimento de atividades que demandem dos estudantes mais do que a pura memorização: o atirar longe, o lançar para diante, o lançar à frente, o projetar.

\section{Referências}

Almeida, A., \& Sasseron, L. H. (2013). As ideias balizadoras necessárias ao professor ao planejar e avaliar a aplicação de uma sequência de ensino investigativo. In IX Congreso Internacionalsobre Investigación en Didáctica delasciencias. Girona, Espanha. Recuperado de https://www.raco.cat/index.php/Ensenanza/article/viewFile/307073/397053

Bacich, L., \& Moran, J. (2018). Metodologias ativas para uma educação inovadora: uma abordagem téorico-prática. Porto Alegre: Penso. Recuperado de https://integrada. minhabiblioteca.com.br/\#/books/9788584291168/

Bertoldi, A. D., Possel, M. C., Daron, R., Costa, R. C. T., \& Borba, S. de. (2011). Identificando atividades de design na educação básica por meio do método Card Analysing. InfoDesign, 8(3), 20-25. Recuperado de https://www.infodesign.org.br/ infodesign/article/view/153

Borges, M. C., Chachá, Silvana, G. F., Quintana, S. M., Freitas, L. C. C., \& Rodrigues, M. L. V. (2014). Aprendizado baseado em problemas. Revista da Faculdade de Medicina de Ribeirão Preto e do Hospital das Clínicas da FMRP, 47(3), 301-307. Recuperado de http://www.revistas.usp.br/rmrp/article/view/86619

Bruno, G. S., \& Carolei, P. (2018). Analise semântica de resumos científicos como recurso para evidenciar pontos críticos. In Educação em Ciências em múltiplos contextos - Atas do XVIIEncontro Nacional de Educação em Ciências, XVII ENEC, I Seminário Internacional de Educação em Ciências, I SIEC. Viana do Castelo: Instituto Politécnico de Viana do Castelo. Escola Superior de Educação. Recuperado de https://www.gsbruno.com.br/enec2017 
Buck Institute for Education. (2008). Aprendizagem baseada em projetos: Guia para professores de ensino fundamental e médio. 2. ed. Porto Alegre: Artmed.

Burnette, C. (2005a). IDESiGN_Design Thinking \& Other Disciplines. Recuperado em 31 de julho, 2018, de http://www.idesignthinking.com/01 whyteach/02whyteach.html

Burnette, C. (2005b). IDESiGN_Evaluating What is Learned. Recuperado em 31 de julho, 2018, de http://www.idesignthinking.com/06assessment/01assess.html

Burnette, C. (2005c). IDESiGN_Traditional Versus Design Based Teaching. Recuperado em 31 de julho, 2018, de http://www.idesignthinking.com/03teachdt/02teachdt.html

Camargo, G. H. de, Motokane, M. T., \& Castro, R. G. de. (2016). A argumentação em uma sequência didática investigativa sobre biodiversidade. In Revista da SBEnBio Número 9 - 2016 VI Enebio e VIII Erebio Regional 3 (pp. 2244-2255). Belo Horizonte.

Carvalho (org.), A. M. P. de. (2004). Ensino de Ciências: unindo a pesquisa e a prática. São Paulo: Thomson Learning.

Carvalho, A. M. P. de. (2013). O Ensino de Ciências e a proposição de sequências didáticas investigativas. In Ensino de Ciências por Investigação: Condições para implementação em sala de aula. São Paulo: Cengage Learning.

Dresch, A., Lacerda, D. P., \& Júnior, J. A. V. A. (2015). Design Science research: método de pesquisa para avanço da ciência e tecnologia. Porto Alegre: Bookman.

Dunne, A., \& Raby, F. (2013). Speculative everything: design, fiction, and social dreaming. Cambridge. MA: MIT Press. Cambridge: MIT Press.

FEBRACE. (n.d.). O que é FEBRACE. Recuperado em 20 de janeiro, 2018, de http:// febrace.org.br/o-que-e-a-febrace/

FEBRACE, \& Intel. (2018). APICE - Aprendizagem Interativa em Ciências. Recuperado em 31 de julho, 2018, de http://apice.febrace.org.br/

Fontoura, A. M. (2002). EdaDe: A educação de crianças e jovens através do Design. (Tese de Doutorado). Universidade Federal de Santa Catarina. Recuperado de https:// repositorio.ufsc.br/handle/123456789/82554

Latour, B. (2012). Reagregando o social: uma introdução à teoria do ator-rede. São Paulo: EDUSC.

Martins, B. M. R., \& Couto, R. M. de S. (2016). Design como prática educativa: estudos de caso da Aprendizagem Baseada em Design. Blucher Design Proceedings, (May), 56255638. https://doi.org/10.5151/despro-ped2016-0534

Miller, W. R. (1988). A definição de design. Tradução de João de Souza Leite. Recuperado de http://feiramoderna.net/ufes/projeto1/MILLER-A-definicao-de-Design.pdf 
Moreira, L. C., Souza, G. S. de, \& Almassy, R. C. B. (2014). As atividades investigativas e a resolução de problemas no ensino de biologia: Limites e possibilidades. Revista da Associação Brasileira de Ensino de Biologia.

Motokane, M. T. (2015). Sequências Didáticas Investigativas e Argumentação no Ensino de Ecologia. Revista Ensaio, 115-137. https://doi.org/10.1590/1983-2117201517s07

Nelson, D. (2009). How Does Design-Based Learning Work? Recuperado em 31 de julho, 2018, de http://www.cpp.edu/ dnelson/methodology/index.html

Oguz-unver, A. Arabacioğlu, S. (2014). A comparison of inquiry-based learning (IBL), problem-based learning (PBL) and project-based learning (PJBL). Academia Journal of Educational Research, 2(July), 120-128. https://doi.org/10.15413/ajer.2014.0129

Organização das Nações Unidas. (2017). Plataforma Agenda 2030. Recuperado em 12 de janeiro, 2018, de http://www.agenda2030.org.br/

Ramos, D. C. (2016). O raciocínio abdutivo em atividades de modelagem matemática. Universidade Estadual de Londrina. Recuperado de http://www.uel.br/pos/mecem/ arquivos_pdf/Dissertacao_Daiany Cristiny Ramos.pdf

Rodrigues, B. A., \& Tarciso, A. (2008). O Ensino de Ciências por Investigação: reconstrução histórica. XI Encontro de Pesquisa Em Ensino de Física, 1-12. Recuperado de http://www.contagem.mg.gov.br/arquivos/comunicacao/femcitec_ensinodeciencia06. pdf

Salvador, D. F., Rolando, L. G. R., Oliveira, D. B. de, \& Vasconcellos, R. F. R. R. (2014). Aplicando os princípios da Aprendizagem Baseada em Problemas como modelo instrucional no contexto de uma feira de ciências. Revista Electrónica de Enseñanza de Las Ciencias, 13(3), 292-317. Recuperado de http://reec.uvigo.es/volumenes/volumen13/ REEC_13_3_3_ex839.pdf

Sasseron, L. H. (2013). Interações discursivas e investigação em sala de aula: o papel do professor. In Ensino de Ciências por Investigação: Condições para implementação em sala de aula. Cengage Learning.

Sasseron, L. H., \& Carvalho, A. M. P. de. (2011). Alfabetização científica: uma revisão bibliográfica. Investigações Em Ensino de Ciências, 16(1), 59-77. Recuperado de https:// www.if.ufrgs.br/cref/ojs/index.php/ienci/article/view/246/172

Scarpa, D. L., \& Silva, M. B. (2013). A Biologia e o ensino de Ciências por investigação: dificuldades e possibilidades. In Ensino de Ciências por Investigação: Condições para implementação em sala de aulas. São Paulo: Cengage Learning.

Simon, H. A. (1996). The sciences of the artificial. 3rd ed. Cambridge: MIT Press. 
Solino, A. P., \& Gehlen, S. T. (2014). Abordagem Temática Freireana e o Ensino de Ciências por Investigação: Possíveis relações epistemológicas e pedagógicas. Investigações Em Ensino de Ciências, 19(1), 141-162. Recuperado de https://www.if.ufrgs.br/cref/ojs/ index.php/ienci/article/view/100/71

Trivelato, S. L. F., \& Tonidandel, S. M. R. (2015). Ensino por Investigação: eixos organizadores para sequências de ensino de biologia. Ensaio: Pesquisa em educação em Ciências (Belo Horizonte), 17(spe), 97-114. https://doi.org/10.1590/1983-2117201517s06 Vianna, M., Vianna, Y., Adler, I. K., Lucena, B., \& Russo, B. (2012). Design thinking: inovação em negócios. Rio de Janeiro: MJV press.

Vygotsky, L. S. (2008). Pensamento e Linguagem. 4. ed. São Paulo: Martins Fontes.

Zômpero, A. F., \& Laburú, C. E. (2011). Atividades investigativas no ensino de ciências: aspectos históricos e diferentes abordagens. Ensaio: Pesquisa em Educação em Ciências (Belo Horizonte), 13(3), 67-80. http://dx.doi.org/10.1590/1983-21172011130305

\section{Gabriel da Silva Bruno}

http://orcid.org/0000-0002-5238-0557

Universidade Anhembi Morumbi

Escola de Ciências da Saúde

São Paulo, São Paulo, Brasil

gasilvabruno@gmail.com

Paula Carolei

http://orcid.org/0000-0002-1592-9731

Universidade Federal de São Paulo

Universidade Aberta do Brasil

São Paulo, São Paulo, Brasil

pcarolei@gmail.com

Submetido em 01 de Fevereiro de 2018

Aceito em 01 de Novembro de 2018

Publicado em 15 de Dezembro de 2018 